\title{
Application of Box - Jenkins ARIMA (p, d, q) Model for Stock Price Forecasting and Detect Trend of S\&P BSE Stock Index: An Evidence from Bombay Stock Exchange
}

Rahul Kumar Si ${ }^{1 *}$, Shishir Kumar Padhan ${ }^{2}$, Dr. Bidyadhara Bishi ${ }^{3}$

${ }^{1}$ Statistical Assistant, Tobacco Board, Ministry of Commerce \& Industry, Govt. of India, Guntur, Andhra Pradesh - 522004, India

${ }^{2}$ Senior Statistical Officer, NSO (FOD), Ministry of Statistics \& PI, Govt. of India, Vellore, Tamil Nadu - 632009, India

${ }^{3}$ Research Scholar, P.G. Department of Statistics, Sambalpur University, Jyotivihar, Burla, Sambalpur, Odisha - 768019, India

DOI: $\underline{10.36347 / \text { sipms.2020.v07i07.006 }}$

| Received: 14.07.2020 | Accepted: 22.07.2020 | Published: 30.07.2020

*Corresponding author: Rahul Kumar Si

Abstract

Original Research Article

STOCK price prediction is an important topic in financial statistics which stimulates the interest over the years to develop better predictive models. It also provides a way to predict and perhaps avoid the risk of large adverse changes in price. Autoregressive Integrated Moving Average (ARIMA) methodology: "A real time risk prediction technique, flexible in computing and universal approximate because of its simplicity and wide acceptability that can be applied to a wide range of forecasting problems with a high degree of accuracy for the convenience of predicting the future value in share market and gives a better future scope for investment" is used in this paper to forecast the S\&P BSE stock price. Before forecasting the stock prices using ARIMA model, a trend analysis was conducted on the sample data to find out the nature of the time series, i.e. upward trend, stationary or downward trend. The skewness and kurtosis also give the basic idea about the shape of the time series data. Augmented Dickey - Fuller (ADF) and Phillips - Perron (PP) unit root test were applied to know about the stationarity of the time series data. A robust model was identified by comparing the smallest value of Akaike's Information Criteria (AIC) and Bayesian Information Criteria (BIC). The parameters: R-Square, Adjusted R-Square, S.E of regression and Durbin-Watson statistic were estimated to regulate best ARIMA model. After parameter estimation is done, it is necessary to verify the satisfactoriness of the estimated model. The value of serial correlation was studied to verify that the series of correlation residuals is white noise or not. After the speculative model has been fitted, Ljung-Box Q statistic was applied for diagnostic checking or suitability of the model. Forecasting is the next step of the ARIMA model, which is an essential part of time series analysis. It is the predicted values based on identified past values of that variable or other related variable. Mean Absolute Percentage Error (MAPE) was calculated to determine the forecast accuracy as well as performance of the model.

Keywords: Stock, Forecast, ARIMA, Correlogram, Ljung-Box Q statistic and MAPE.

Copyright @ 2020: This is an open-access article distributed under the terms of the Creative Commons Attribution license which permits unrestricted use, distribution, and reproduction in any medium for non-commercial use (NonCommercial, or CC-BY-NC) provided the original author and source are credited.

\section{INTRODUCTION}

A stock is a share in the aspiration of a company. It represents the claim on the company's assets and incomes. It is also known as equity of share and a portion of the ownership in a corporate sector by an indivisual. Hence, a stock of a company entitles its share holders in its profit and issuing shares by a corporate company can mobilize huge capitals. Most of these shares are traded in exchanges, where buyers and sellers will meet and make a decision on a price is called 'Stock Market'. It is the aggregation of buyers and sellers of stocks and represents the ownership of a business. Transaction in stock market means the transfer of money from a seller to buyer for equities when they agree on a certain price and is facilitated by a stock exchange.

Stock market is a place where investors, whether Indians or foreigners can invest or take their funds for capital appreciation. Their decision to invest or withdraw the funds depends upon the numerous factors. For this cause Indian stock market plays a significant role in the growth of Indian economy and every movement on it puts an impact on the performance of the economy.

The Indian stock market had seen various updown since 1991, after the government implemented the LPG, i.e., Liberalization, Privatization and 
Globalization. According to the Economic Survey 2019-20, the Gross Domestic Product (GDP) growth rate is estimated to be 5\% in 2019-20 as compared to $6.8 \%$ in 2018-19. The GDP growth decelerated for the sixth consecutive quarter. In 2020-21, India's GDP growth rate is expected to be in the range of $6.0 \%$ $6.5 \%$. The Consumer Price Index (CPI) based inflation increased from $3.7 \%$ in $2018-19$ to $4.1 \%$ in $2019-20$. This increase was mainly due to food inflation. The Wholesale Price Index (WPI) based inflation decreased from $4.3 \%$ in $2018-19$ to $1.5 \%$ in $2019-20$. India's Current Account Deficit (CAD) decreased from $2.1 \%$ of GDP in 2018-19 to $1.5 \%$ of GDP in 2019-20. The fiscal deficit for 2019-20 is estimated at 3.3\% and the primary deficit for the year is estimated at $0.2 \%$ of GDP (primary deficit is the fiscal deficit excluding the interest payments). As of November 2019, fiscal deficit stood at $114.8 \%$ of the budgeted level and India having become the fifth largest economy in the world in 2019. With this growth rate, India also became the fastest growing economy and aspiring to be the third largest with a $\$ 5$ trillion by 2025 .

Stock markets are dynamic in nature, means prediction of stock market is a complex process because the indices are highly fluctuating, as a result of increase or decrease that characterize the stock price. Forecasting financial time series such as stock market has drawn considerable attention among applied researchers because of the vital role in the economy of any nation. Stock market forecasters focus on developing successful approach for predict the value of stock index, ultimate aiming to high profit using well defined trading strategies. The main idea behind the stock market prediction is achieving best result and minimizes the risk.

Stock price prediction has always attracted interest because of the direct financial benefits and the associated complexity. The stock prices reflect all information about the stocks and also the expectations of the future performances of corporate sector. As a result, if stock prices reflect these assumptions in real, then it should be used as a major indicator for the economic activities [1]. Hence the dynamic relationship between stock prices and forecast values contains academic interest as well as policy implications.

\section{Bombay Stock Exchange - A Bird's Eye View}

Established in 1875, the BSE (formerly known as Bombay Stock Exchange Ltd.) is Asia's oldest stock exchange was founded by an influential businessman Premchand Roychand, located at Dalal Street, Mumbai. The BSE is the world's 10th largest stock exchange with an overall market capitalization of more than \$2.2 trillion. Today, BSE is the world's number one exchange in the world in terms of the number of listed companies (over 5400). It is the world's 5th most active in terms of number of transaction handle through its electronic trading system. On $31^{\text {st }}$ August1957, the BSE becomes the first stock exchange to be recognised by Indian Government under the Securities Contracts Regulation Act. Sensex is India's first and most popular stock market benchmark index of BSE and calculated on a "Market Capitalization-Weighted" methodology of 30 component stocks representing large, wellestablished and financially sound companies across key sectors in 1986. It is being calculated on a free-float market capitalization methodology. The free-float market capitalization-weighted methodology is a widely followed index construction methodology on which majority of global equity indices are based; all major index providers like MSCI, FTSE, STOXX, S\&P and Dow Jones. In the same year, it developed the S\&P BSE Sensex index giving the BSE a means to measure the overall performance of the exchange. In 2000, the BSE used this index to open its derivative market, trading S\&P BSE Sensex future contracts. The development of S\&P BSE Sensex options along with equity derivatives expanding the BSE's trading platform.

\section{REVIEW OF LITERATURE}

Forecasting of stock price is a prominent issue for the past several decades. Financial managers, business analysts, academicians and investors are interested for predicting highly accurate future stock price as it gives high returns. Therefore it will help the investors to give a better view and predict the stock price in a reference period of time.

Forecasting can be done on the basis of two different techniques; statistical techniques and artificial intelligence techniques [2]. But the performance of statistical technique is better as compared to artificial intelligence techniques [3]. The stock price prediction is regarded as one of the most difficult task to achieve due to its complex nature [4]. This remains an inspiring aspect to evolve new predictive models or improve the existing ones [5]. However, still there is a lot of debate as to which method is the most appropriate.

Forecasting and policy analysis have been conducted using structural macroeconomic model based on Cowels Commission Approach [6,7]. The initial relative success of this approach was impeded by Lucas Critique for parameter estimation from an econometric model [8]. These econometric models have been improved depending on their applications [9].

Since it is necessary to identify a model to analyse the trends of stock price with relevance information for decision making, it recommends that transforming the time series using ARIMA is better approach than forecasting directly, as it give more accurate result [10]. It is an applied mathematical analysis model that uses static information into either discern the data set or to predict future trend [11] and applied to solve the real world problems in the stock market by forecasting the stock prices along with 
performance measure, which helps the new investors as well as existing ones to make a strategic decision [12]. It is an efficient and robust econometric model used to forecast the financial time series data for short term period $[13,14]$.

The popularity of the Box-Jenkins methodology to ARIMA models was excited when empirical studies [15-22], using real data showed that Box-Jenkins ARIMA was equally or more accurate as compared to simple methods, when post-sample comparisons were made. Today, after a valid arguments and considerable debates, it is accepted by a large number of researchers that in empirical tests BoxJenkins is an accurate method for post-sample time series forecasting, at least in the domains of business and economic applications where the level of randomness is lower and constancy of pattern or relationships can be assured.

Askari \& Askari [23], compare the ARIMA model with the Conventional Grey model and Modified Grey Model using fourier series on the noisy gold price data whereas, Wong, Tu \& Wang [24], compare the ARIMA model with Vector ARIMA model with Fuzzy Time Series especially Heuristic Model and observed better forecasting ability in short term period. Ojo \& Olatayo [25], focus on the estimation and performance of Subset Autoregressive Integrated Moving Average (SARIMA) and compared with ARIMA model using Marquardt Algorithm and Newton-Raphson Iterative Method and examine the performance of the model and residual variance using AIC and BIC [26], but Root Mean Square Forecast Error (RMSFE) and Mean Absolute Percentage Forecast Error (MAPFE) were used by Shittu \& Yaya [27], to measure long memory properties of UK Pound and US Dollar exchange rate and compare the performance of ARIMA and AFRIMA is a combination of Fuzzy Regression model and ARIMA model for stationary time series [28].

Mandal et al., [29], analysed 56 time series of Indian stocks from different sectors to determine the $85 \%$ of forecasting accuracy using ARIMA models, whereas Jadhav et al., [30], analysed the historical data of 6 years for Indian stock market using six different models on monthly closing stock index of Sensex and concluded that ARIMA model helps in predicting fairly accurate values of the future stock indices and satisfies all the condition for the "Goodness of Fit". In a similar study, Edward \& Manoj [31], developed and applied ARIMA model in Indian stock prices in 6 sectors: Automobiles, Banking, Health Care, Information Technology Oil \& Gas and Power Sector for daily actual data of nine years to forecast the stock prices.

Simons \& Laryea [32], studied the weak form of the efficient market hypothesis of Ghana, Mauritius, Egypt and South Africa using ARIMA model to generate one period forecast. In a similar study,
Rahman \& Hossain [33], found that the fitted values derived from the models and the actual data is all but well fitted. Majhi et al., [34], used Adaptive Bacterial Foraging Optimization (ABFO) and Bacterial Foraging Optimization (BFO) based technique to predict stock market indices and compared with the Genetic Algorithm based technique. The relative predictive power of ARIMA, VAR and ECM models were examined by Uko \& Nkoro [35].

The purpose of this paper is to examine the post-sample forecasting performance of ARIMA models and detect trend in order to determine the contribution of each of its elements. That is, dealing with stationarity, invertibility and parsimony are the three important parameters are used to identification, estimation and diagnostic checking respectively [36]. When alternative ways of dealing with and extrapolating the trend are provided, ARIMA models are more accurate than the corresponding time series methods that extrapolate the trend in the same way. These encouraging results suggest that statistical theory and empirical results are in agreement and that more appropriate ways of dealing with the trend in ARIMA or any other type of time series.

\section{RESEARCH METHODOLOGY}

The ARIMA methodology adopted in this study takes into account historical data and decomposes it into an Autoregressive (AR) process, where there is a memory of past events; an integrated (I) process, which accounts for stabilizing or making the data stationary, making it valid for forecast; and a Moving Average (MA) of the forecast errors, such that the longer the historical data, the more accurate the forecast will be, as it learns over time. ARIMA model therefore have three model parameters, one for the AR(p) process, one for the $\mathrm{I}(\mathrm{d})$ process, and one for the $\mathrm{MA}(\mathrm{q})$ process, all combined and interacting with each other and recomposed into the ARIMA (p,d,q) model.

In order to identify the proper $\mathrm{p}, \mathrm{d}$, and $\mathrm{q}$ parameters of the model and forecast S\&P BSE stock price, the Box-Jenkins algorithm was adopted as follows: (1) Model Identification, (2) Parameter Estimation, (3) Diagnostic Checking, (4) Forecasting and (5) Forecast Accuracy.

Model identification involves determining whether a particular model with specific $\mathrm{p}, \mathrm{d}$ and $\mathrm{q}$ parameters is a good statistical fit. This study employed ADF and PP unit root test to identify the d parameter. After determined the correct order of differencing, the best ARMA model was identified by a.c.f, p.a.c.f and their resulting correlograms. The highly subjective nature of the a.c.f and p.a.c.f methods made alternative objective methods for identifying ARMA models imperative. The $\mathrm{p}$-th order autoregressive and $\mathrm{q}$-th order moving average parameters are identified by least value of AIC and BIC. Before doing this a trend analysis was 
conducted on the sample data to find out the nature of the time series. The next step is estimating the parameters of the appropriate ARMA to best fit to the $S$ $\&$ P BSE stock price. The penalty function statistics which was employed in this study include: R-square, Adjusted R-square, S.E of regression and DurbinWatson Statistic. Diagnostic checking involves ensuring that the estimated model is a reasonable fit to the data. In order to ensure that the estimated model is a reasonable fit to the BSE data, this study used LjungBox Q statistic to examine the residuals obtained from the estimated model for signs of autocorrelation and if the residuals are white noise, it suggests a good fit. Forecasting is the next step of the ARIMA model, which is an essential application of time series analysis. It is the predicted values based on identified past values of that variable or other related variable. Another essential check will be to test the robustness of the selected model by estimating MAPE to determine the forecast accuracy as well as performance of the model.

\section{MATHEMATICAL STRACTURE OF BOX - JANKINS ARIMA (p,d,q) MODEL}

The ARIMA model was established in 1990s for prediction of time series data [37]. The popularity of this model was exhausted when empirical studies [3842] using real data showed that simple methods are more accurate than ARIMA method. It is often referred as ARIMAX model as well as dynamic regression, when it includes other time series as an input variable and offers great flexibility in univariate time series model identification, parameter estimation and forecasting [43]. An ARIMA (p,d,q) model is defined as an I (d) process whose d-th order difference follow a stationary ARMA $(p, q)$ process. In polynomial form:

$$
\emptyset(\mathrm{B}) \mathrm{Y}_{\mathrm{t}}=\theta_{\mathrm{q}}(\mathrm{B}) \varepsilon_{\mathrm{t}}
$$

Where, $\varnothing(\mathrm{B})$, the generalised autoregressive operator, is a polynomial of degree $\mathrm{p}+\mathrm{d}$, with exactly $\mathrm{d}$ zeros equal to unity and all the others outside the unit circle. So

$$
\emptyset(\mathrm{B})=\varphi_{\mathrm{p}}(\mathrm{B})(1-\mathrm{B})^{\mathrm{d}}=\varphi_{\mathrm{p}}(\mathrm{B}) \nabla^{\mathrm{d}}
$$

Where $\varphi_{\mathrm{p}}(\mathrm{B})$ is a stationary autoregressive operator of order $\mathrm{p}$, and the operator $\nabla$ reflects a differencing.

An ARIMA $(2,1,2)$ model means, it contains two autoregressive (p) parameters, two moving average (q) parameters and differencing once to obtain the stationarity.

- If $\mathrm{d}=0$, the models becomes ARMA and is considered as linear stationary model.
- If $\mathrm{d}>0$, the models becomes ARIMA and is considered as linear non stationary model.

In other words If we replace $\nabla^{d} Y_{t}$ by $W_{t}$, the ARIMA (p, d, q) process $\left\{Y_{t}\right\}$ is reduced to an $\operatorname{ARMA}(p, q)$ process $\left\{W_{t}\right\}$. Should a realisation show evidence that, $\mathrm{E}\left(\mathrm{W}_{\mathrm{t}}\right) \neq 0$, then the series $\mathrm{w}_{\mathrm{t}}$ is replaced by $\left\{\mathrm{z}_{\mathrm{t}}=\mathrm{w}_{\mathrm{t}}-\overline{\mathrm{w}}\right\}$. Having obtained the $\left\{\mathrm{w}_{\mathrm{t}}\right\}$ fit, the corresponding $\left\{\mathrm{y}_{\mathrm{t}}\right\}$ fit can be obtained by the operation inverse to the differencing $\nabla^{\mathrm{d}}$.

ARIMA model is based on ARMA model and the difference is that, it converts a non stationary data to a stationary data and widely used to predict linear time series data [44]. Before working on it, we have to introduce ARMA model is a combination of $\mathrm{p}$-th order $\mathrm{AR}$ and $\mathrm{q}$-th order MA process. It was formulated by the works of Yule [45], Slustky [46], Walker [47] and Yoglom [48]. A time series is a sequence of random variables $\left\{Y_{t}\right\}$, which are not generally independent, but serially correlated. A linear process of the form:

$$
\begin{array}{r}
\mathrm{Y}_{\mathrm{t}}=\varphi_{1} \mathrm{Y}_{\mathrm{t}-1}+\varphi_{2} \mathrm{Y}_{\mathrm{t}-2}+\cdots+\varphi_{\mathrm{p}} \mathrm{Y}_{\mathrm{t}-\mathrm{p}}+\varepsilon_{\mathrm{t}}-\theta_{1} \varepsilon_{\mathrm{t}-1} \\
-\theta_{2} \varepsilon_{\mathrm{t}-2}-\cdots-\theta_{\mathrm{q}} \varepsilon_{\mathrm{t}-\mathrm{q}} \cdots \cdots(1)
\end{array}
$$

Satisfying the Gaussian Assumption: $\left\{\varepsilon_{\mathrm{t}}\right\}$ is a structure less process of independent normal variable with zero mean and constant variance, called a White Noise Process. Symbolically:

$$
\varepsilon_{\mathrm{t}} \sim \mathrm{WN}\left(0, \sigma_{\varepsilon}^{2}\right)
$$

Without loss of generality, choose $\mathrm{p}$ and $\mathrm{q}$ sufficiently small, such that: $\varphi_{\mathrm{p}}, \theta_{\mathrm{q}} \neq 0$

Introducing the backshift operator $\mathrm{B}$, with the property,

$$
\mathrm{BZ}_{\mathrm{i}}=\mathrm{Z}_{\mathrm{i}-1}
$$

For any process $\left\{Z_{t}\right\}$ and any time i, equ. (1) can be written as:

$$
\varphi_{\mathrm{p}}(\mathrm{B}) \mathrm{Y}_{\mathrm{t}}=\theta_{\mathrm{q}}(\mathrm{B}) \varepsilon_{\mathrm{t}}
$$

When, $\mathrm{q}=0$, it is termed as $\mathrm{p}$ th order Autoregressive Process or AR (p) and

$$
\mathrm{p}=0 \text {, it is termed as } \mathrm{q} \text { th order Moving }
$$
average Process or MA (q)

For general,p and $q$, it is an ARMA (p,q) process. It is called proper when it does not degenerate to either AR (p) or MA (q). Simple example and alternative terms of AR (1), MA (1) and ARMA (1,1) are shown in Table-1.

Table-1: Example and alternative terms of AR (1), MA (1) and ARMA (1,1)

\begin{tabular}{|l|c|c|}
\hline Process & Example & Alternative form \\
\hline AR $(1)$ & $Y_{t}=\varphi Y_{t-1}+\varepsilon_{t}$ & $(1-\varphi B) Y_{t}=\varepsilon_{t}$ \\
\hline MA $(1)$ & $Y_{t}=\varepsilon_{t}+\theta \varepsilon_{t-1}$ & $Y_{t}=(1+\theta B) \varepsilon_{t}$ \\
\hline ARMA $(1,1)$ & $Y_{t}=\varphi Y_{t-1}+\varepsilon_{t}+\theta \varepsilon_{t-1}$ & $(1-\varphi B) Y_{t}=(1+\theta B) \varepsilon_{t}$ \\
\hline
\end{tabular}


Before going to do ARMA approach in details, a stationarity test was conducted to find out the nature of the time series data. The Box-Jenkins approach suggests short and long term differencing to achieve stationarity in the mean and logarithmic or power transformation to achieve stationarity in the variance. The value of such transformations to improve postsample forecasting accuracy has also been debated and no agreement has been reached as to whether or not transformations are helpful [49]. At the empirical level there is also no evidence that logarithmic or power transformations improve post-sample forecasting accuracy [50]. But some series could be better made stationary through differencing while others through linear de-trending.

The popular way of finding a unit root is to examine mean and covariance of a series, if the mean is increasing over period of time. Such type of test is called Dickey - Fuller unit root test, proposed by, Dickey \& Fuller [51]. The possible approach to examine the t-value on coefficients, but F-test is conducted when the a.c.f for the variable tends to zero as the length of lag increases. If a.c.f tends to zero quickly, then the variable is stationary; otherwise non stationary.

Consider the simple AR(1) model:

$$
\mathrm{y}_{\mathrm{t}}=\varphi \mathrm{y}_{\mathrm{t}-1}+\varepsilon_{\mathrm{t}} \text { where } \varepsilon_{\mathrm{t}} \sim \mathrm{WN}\left(0, \sigma^{2}\right)
$$

Under the test hypothesis,

$$
\begin{gathered}
\mathrm{H}_{0}: \varphi=1 \Rightarrow \mathrm{y}_{\mathrm{t}} \sim \mathrm{I}(1) \\
\mathrm{H}_{1}:|\varphi|<1 \Rightarrow \mathrm{y}_{\mathrm{t}} \sim \mathrm{I}(0)
\end{gathered}
$$

The test statistic is

$$
\mathrm{t}_{\varphi=1}=\frac{\widehat{\varphi}-1}{\operatorname{SE}(\widehat{\varphi})}
$$

Where $\widehat{\varphi}$ is the least square estimate and $\operatorname{SE}(\widehat{\varphi})$ is the S.E. estimate. If $\left\{y_{t}\right\}$ is stationary, then it can be shown as [52].

$$
\begin{gathered}
\sqrt{\mathrm{T}}(\widehat{\varphi}-\varphi) \stackrel{\mathrm{d}}{\rightarrow} \mathrm{N}\left(0,\left(1-\varphi^{2}\right)\right) \\
\Rightarrow \widehat{\varphi} \underset{\sim}{\mathrm{A}} \mathrm{N}\left(\varphi, \frac{1}{\mathrm{~T}}\left(1-\varphi^{2}\right)\right)
\end{gathered}
$$

and it follows that $t_{\varphi=1} \underset{\sim}{A} \mathrm{~N}(0,1)$. Under the null hypothesis, non stationarity of the above result gives,

$$
\widehat{\varphi} \underset{\sim}{\mathrm{A}} \mathrm{N}(1,0)
$$

Under the unit root null, $\left\{\mathrm{y}_{\mathrm{t}}\right\}$ is not stationary. In other words, if $\varepsilon_{\mathrm{t}}$ is autocorrelated, then the chance of rejecting a correct null hypothesis is high. Hence, augmenting the test using lags of the dependent variable would be necessary and to use Augmented Dickey Fuller test, proposed by Said \& Dickey [53]. Under the null hypothesis, a time series $\left\{\mathrm{y}_{\mathrm{t}}\right\}$ is $\mathrm{I}(1)$ against $\mathrm{I}(0)$, assuming that the dynamics in the data have an ARMA stracture. The ADF test is based on estimating the test regression:

$$
y_{t}=\beta^{\prime} D_{t}+\varphi y_{t-1}+\sum_{j=1}^{p} \psi_{j} \Delta y_{t-j}+\varepsilon_{t}
$$

Where $D_{t}$ is a vector of deterministic terms and the $\mathrm{p}$ is lagged difference terms. $\Delta \mathrm{y}_{\mathrm{t}-\mathrm{j}}$ are used to approximate the ARMA stracture of the errors and the value of $\mathrm{p}$ is set, so that the error $\varepsilon_{\mathrm{t}}$ is serially uncorrelated. If $\mathrm{p}$ is too small, then the remaining serial correlation in the errors will bias the test. If $\mathrm{p}$ is too large, then the power of the test will suffer. For stable size of the test and minimal power loss, first set an upper bound $\mathrm{p}_{\mathrm{max}}$ for $\mathrm{p}$. Next estimate the ADF test regression with $\mathrm{p}=\mathrm{p}_{\mathrm{max}}$. If the absolute value of $\mathrm{t}$ statistic for testing the significance of the last lagged difference is greater than 1.6 , then set $\mathrm{p}=\mathrm{p}_{\mathrm{m} \text { ax }}$ and unit root test is performed. Otherwise, the lag length is decreased by 1 and the process is repeated [54]. For determining $\mathrm{p}_{\mathrm{max}}$, Schwert defined [55]:

$$
\mathrm{p}_{\text {max }}=\left(12\left(\frac{\mathrm{T}}{100}\right)^{1 / 4}\right)
$$

The ADF $\mathrm{t}$ - statistic and normalized bias statistic based on least square estimates of equ. (3) are given by

$$
\begin{gathered}
\mathrm{ADF}_{\mathrm{t}}=\mathrm{t}_{\varphi=1}=\frac{\widehat{\varphi}-1}{\operatorname{SE}(\varphi)} \\
\mathrm{ADF}_{\mathrm{n}}=\frac{\mathrm{T}(\widehat{\varphi}-1)}{1-\widehat{\Psi}_{1}-\widehat{\Psi}_{2}-\cdots-\widehat{\Psi}_{\mathrm{p}}}
\end{gathered}
$$

Both DF and ADF test with no drift and no trend; with trend and no drift is summarizes in Table-2.

Table-2: Equations estimated for DF and ADF test

\begin{tabular}{|c|c|c|}
\hline DF test & ADF test & No Drift, No Intercept \\
\hline $\mathrm{y}_{\mathrm{t}}=\varphi \mathrm{y}_{\mathrm{t}-1}+\varepsilon_{\mathrm{t}}$ & $\mathrm{y}_{\mathrm{t}}=\varphi \mathrm{y}_{\mathrm{t}-1}+\sum_{\mathrm{j}=1}^{\mathrm{p}} \psi_{\mathrm{j}} \Delta \mathrm{y}_{\mathrm{t}-1}+\varepsilon_{\mathrm{t}}$ & \\
\hline $\mathrm{y}_{\mathrm{t}}=\beta_{0}+\varphi \mathrm{y}_{\mathrm{t}-1}+\varepsilon_{\mathrm{t}}$ & $\mathrm{y}_{\mathrm{t}}=\beta_{0}+\varphi \mathrm{y}_{\mathrm{t}-1}+\sum_{\mathrm{j}=1}^{\mathrm{p}} \psi_{\mathrm{j}} \Delta \mathrm{y}_{\mathrm{t}-1}+\varepsilon_{\mathrm{t}}$ & No Drift with Intercept \\
\hline $\mathrm{y}_{\mathrm{t}}=\beta_{0}+\beta_{1} \mathrm{t}+\varphi \mathrm{y}_{\mathrm{t}-1}+\varepsilon_{\mathrm{t}}$ & $\mathrm{y}_{\mathrm{t}}=\beta_{0}+\beta_{1} \mathrm{t}+\varphi \mathrm{y}_{\mathrm{t}-1}+\sum_{\mathrm{j}=1}^{\mathrm{p}} \psi_{\mathrm{j}} \Delta \mathrm{y}_{\mathrm{t}-1}+\varepsilon_{\mathrm{t}}$ & With Intercept and trend \\
\hline
\end{tabular}


The PP unit root test, named after Phillips and Perron [56], difference from the ADF test mainly in how they deals with serial correlation and Heteroskedasticity in the errors. In particular, where the $\mathrm{ADF}$ test use a parametric autoregression to approximate the ARMA stracture of the errors in test regression the PP test ignores any serial correlation in the test regression. The test regression becomes:

$$
\Delta \mathrm{y}_{\mathrm{t}}=\beta^{\prime} \mathrm{D}_{\mathrm{t}}+\varphi \mathrm{y}_{\mathrm{t}-1}+\varepsilon_{\mathrm{t}}
$$

Where, $\varepsilon_{\mathrm{t}}$ is $\mathrm{I}(0)$ and may be heteroskedasticity. The PP test correct for any serial correlation and heteroskedasticity in the errors $\varepsilon_{t}$ of the test regression by directly modifying in the test statistic $\varphi_{\mathrm{t}=0}$ and $\mathrm{T} \widehat{\varphi}$. These modified statistics denoted as $\mathrm{Z}_{\mathrm{t}}$ and $\mathrm{Z}_{\varphi}$ and given as:

$$
\begin{gathered}
\mathrm{Z}_{\mathrm{t}}=\left(\widehat{\sigma}^{2} / \widehat{\lambda}^{2}\right)^{-1 / 2} \mathrm{t}_{\varphi=0}-\frac{1}{2}\left(\hat{\lambda}^{2}-\widehat{\sigma}^{2} / \widehat{\lambda}^{2}\right)\left(\mathrm{T} \mathrm{SE}(\widehat{\varphi}) / \widehat{\sigma}^{2}\right) \\
\mathrm{Z}_{\varphi}=\mathrm{T} \hat{\varphi}-\frac{1}{2} \frac{\mathrm{T}^{2} \operatorname{SE}(\widehat{\varphi})}{\widehat{\sigma}^{2}}\left(\hat{\lambda}^{2}-\widehat{\sigma}^{2}\right)
\end{gathered}
$$

The terms $\widehat{\sigma}^{2}$ and $\hat{\lambda}^{2}$ are consistent estimate of the variance parameters

$$
\begin{aligned}
& \sigma^{2}=\lim _{\mathrm{T} \rightarrow \infty} \mathrm{T}^{-1} \sum_{\mathrm{t}=1}^{\mathrm{T}} \mathrm{E}\left(\varepsilon_{\mathrm{t}}^{2}\right) \\
& \lambda^{2}=\lim _{\mathrm{T} \rightarrow \infty} \sum_{\mathrm{t}=1}^{\mathrm{T}} \mathrm{E}\left(\mathrm{T}^{-1} \mathrm{~S}_{\mathrm{T}}^{2}\right)
\end{aligned}
$$

Where $S_{t}=\sum_{t=1}^{T} \varepsilon_{t}$. the sample variance of the least square residuals $\hat{\varepsilon}_{\mathrm{t}}$ is a consistent estimator of $\sigma^{2}$ and the Newly - West long run variance estimate of $\varepsilon_{\mathrm{t}}$ using $\hat{\varepsilon}_{\mathrm{t}}$ is a consistent estimate of $\lambda^{2}$.

Under $\mathrm{H}_{0}: \varphi=0$ the $\mathrm{P} \mathrm{P} \mathrm{Z}_{\mathrm{t}}$ and $\mathrm{Z}_{\varphi}$ statistics have the same asymptotic distribution as the ADF statistic and normalized bias statistic. One advantage of the PP test over the ADF test is that they are robust to general form of heteroskedasticity in the error term $\varepsilon_{\mathrm{t}}$. For a stationary process, by definition $\varphi_{\mathrm{p}}(1) \neq 0$. Taking expectations in equ. (1), we get $\mathrm{E}\left(\mathrm{Y}_{\mathrm{t}}\right)=0$

And for all integer $\mathrm{k}$, defining the autocovariance $\gamma_{\mathrm{k}}$ at $\log \mathrm{k}$ by $\operatorname{Cov}\left[\mathrm{Y}_{\mathrm{t}}, \mathrm{Y}_{\mathrm{t}-\mathrm{k}}\right]$,

$$
\gamma_{\mathrm{k}}=\mathrm{E}\left[\mathrm{Y}_{\mathrm{t}}, \mathrm{Y}_{\mathrm{t}-\mathrm{k}}\right]=\gamma_{-\mathrm{k}}
$$

In particular,

$$
\gamma_{0}=\sigma_{\mathrm{Y}}^{2}
$$

If $\mathrm{E}\left(\mathrm{Y}_{\mathrm{t}}\right)=\mu_{\mathrm{Y}} \neq 0$, then the mean correlated process,

$$
\widetilde{Y}_{\mathrm{t}}=\mathrm{Y}_{\mathrm{t}}-\mu_{\mathrm{Y}}
$$

is replaced by $\left\{Y_{t}\right\}$ and the general process is described by

$$
\underset{\sim}{\Psi}=\left(\varphi_{1}, \varphi_{2}, \ldots \ldots \varphi_{\mathrm{P}}, \theta_{1}, \theta_{2}, \ldots \ldots \theta_{\mathrm{q}}\right)
$$

and $\sigma_{\mathrm{Y}}^{2}$. Alternatively it can be represented by, $\left(\gamma_{0}, \gamma_{1}, \ldots \ldots \ldots \gamma_{\mathrm{p}+\mathrm{q}}\right)$.

Defining the autocorrelation at lag kby, $\rho_{\mathrm{k}}=\frac{\gamma_{\mathrm{k}}}{\gamma_{0}}$, precisely the same information as in $\underset{\sim}{\Psi}$ is contained in $\left(\rho_{1}, \rho_{2} \ldots \ldots \rho_{\mathrm{p}+\mathrm{q}}\right)$ the complete set of autocorrelations $\rho_{1}, \rho_{2} \ldots \ldots$ is termed as Autocorrelation Function (a.c.f). It shows the correlation of the time series with itself lagged by $x$ time units, so that $y$-axis is correlation value and $\mathrm{x}$-axis is the number of lagged unit. For an ARIMA model, AR or MA or both are deciding how many lags should be used. For applying $\mathrm{AR}$ or MA, the values of $\mathrm{p}$ and $\mathrm{q}$ to be set. If the autocorrelation plot shows positive correlation at the first lag, then it is recommended to use AR in relation to lag, if the plot shows, negative correlation, then MA should be used. This will allow to decide what actual value of $\mathrm{p}, \mathrm{d}$ and $\mathrm{q}$ to provide to ARIMA model. The Partial Autocorrelation Function (p.a.c.f) is a set $\pi_{1}, \pi_{2}, \ldots \ldots$ associated with a.c.f and defined as,

$$
\pi_{\mathrm{k}}=\frac{\mid \underline{\underline{\mathrm{P}_{\mathrm{k}}^{*}} \mid}}{\left|\underline{\mathrm{P}_{\mathrm{k}}}\right|}
$$

where, $\mathrm{P}_{\mathrm{k}}=\mathrm{k} x \mathrm{k}$ autocorrelation matrix with general $r$, s-th element $=\rho_{|r-s|}$ and $\mathrm{P}_{\mathrm{K}}^{*}=\mathrm{P}_{\mathrm{k}}$, with every $\mathrm{r}$, k-th element replaced by $\rho_{\mathrm{r}}^{*}$.

Similarly each $\pi_{k}$ gives the conditional correlation between $Y_{t}$ and $Y_{t-k}$, given the intervening $\mathrm{Y}_{\mathrm{t}-1}, \mathrm{Y}_{\mathrm{t}-2}, \ldots \ldots . \mathrm{Y}_{\mathrm{t}-\mathrm{k}+1}$; and each $\pi_{\mathrm{k}}$ can be interpreted as $\varphi_{\mathrm{k}}$ of that A R (k) model which comes closest to representing the process. In other words, it may be a conditional correlation between two variables. An estimated p.a.c.f can be utilized as the guide in combination with expected a.c.f. The forms for a.c.f and p.a.c.f associared with AR, MA and ARMA models are summarized in Table-3.

Table-3: Characteristics of a.c.f \& p.a.c.f for linear process

\begin{tabular}{|l|l|l|}
\hline Process & a.c.f & p.a.c.f \\
\hline AR $(p) \ldots \ldots$. & Damps out & Cuts off after lag $p$ \\
\hline MA $(q) \ldots \ldots$. & Cuts off after lag q & Damps out \\
\hline ARMA $(p, q) \ldots \ldots$ & Damps out & Damps out \\
\hline
\end{tabular}


The estimated a.c.f and p.a.c.f are sets $\left\{\mathrm{r}_{\mathrm{k}}\right\}$ and $\left\{\mathrm{p}_{\mathrm{k}}\right\}$, where $\mathrm{r}_{\mathrm{k}}=\mathrm{c}_{\mathrm{k}} / \mathrm{c}_{0}$ with

$$
\mathrm{c}_{\mathrm{k}}=\frac{1}{\mathrm{n}} \sum_{\mathrm{t}=\mathrm{k}+1}^{\mathrm{n}}\left(\mathrm{y}_{\mathrm{t}}-\overline{\mathrm{y}}\right)\left(\mathrm{y}_{\mathrm{t}-\mathrm{k}}-\overline{\mathrm{y}}\right) ; \mathrm{k}=0,1,2,
$$

Where, $\mathrm{y}_{1}, \mathrm{y}_{2}, \ldots \ldots \mathrm{y}_{\mathrm{n}}$ is a time series of length $\mathrm{n}$.

It will be more difficult to deduce the process from the estimated function due to sampling errors and the fact that the estimated sets are themselves autocorrelated. For an ARMA (p,q) the a.c.f mimics that an AR (p) process after $q-p$ lags, while the p.a.c.f resembles that an MA (q) after $q-p$ lags. For an MA (q) process [57],

$$
\operatorname{Var}\left(\mathrm{r}_{\mathrm{k}}\right) \sim \frac{1}{\mathrm{n}}\left(1+2 \sum_{\mathrm{i}=1}^{\mathrm{q}} \mathrm{r}_{\mathrm{i}}^{2}\right)
$$

While for an AR (p) process [58]

$$
\operatorname{Var}\left(\mathrm{p}_{\mathrm{k}}\right) \sim 1 / \mathrm{n}
$$

When ' $n$ ' is fairly large, the distribution of $r_{k}, k>q$, for an MA (q) and $p_{k}, k>p$ for an AR (p) are roughly normal with zero mean.

In order to identify tentative initial choice of $\mathrm{p}$ and $\mathrm{q}$ the a.c.f and p.a.c.f are calculated and preferably plotted, for the first K-lags. According to Anderson [59],

If $\mathrm{p}_{\mathrm{k}} \sim \mathrm{N}(0,1 / \mathrm{n})$ for $\mathrm{K}>\mathrm{p}, \mathrm{AR}(\mathrm{p})$ is suggested

If $\mathrm{r}_{\mathrm{k}} \sim \mathrm{N}\left(0,1 / \mathrm{n}\left(1+2 \sum_{\mathrm{i}=1}^{\mathrm{q}} \mathrm{r}_{\mathrm{i}}^{2}\right)\right)$ for $\mathrm{K}>\mathrm{q}$, MA (q) is suggested...

If neither equ. (3) nor equ. (4) occurs, then neither a.c.f nor p.a.c.f cut off and an ARMA model is inferred. According to Box \&Jenkins [60], for $p+q \leq 2$, equ. (3) and equ. (4) indicated that the process should be tentatively identified as AR (1), AR (2), MA (1) or MA (2); while if none of these are indicated, by default an ARMA $(1,1)$ would be tried.

Once the model has been identified, its parameter has to be efficiently estimated and resulting fit assessed, mainly by an analysis of residuals, to see whether it can be accepted as to plausible explanation of the series. Firstly,

$$
E\left(Y_{t}\right)=0
$$

is plausible. For otherwise,

$$
\mathrm{z}_{\mathrm{t}}=\mathrm{y}_{\mathrm{t}}-\mathrm{y}
$$

The test is to compare $\bar{y}$ in the usual way, with its $\mathrm{SE}$ assuming $\mathrm{E}\left(\mathrm{Y}_{\mathrm{t}}\right)=0$ is true.

Akaike's Information Criteria is used to select the model that minimizes the negative likelihood penalised by the numbers of parameters [61]. It is denoted as:

$$
\text { A I C }=-2 \log p(L)+2 p
$$

Where, L refers to the likelihood under the fitted model and $p$ is the number of parameters [62]. It is asymptotically optimal in selecting the model, under the assumption that, the true model is not in the candidate set (as is virtually always the case in practice). For comparison purpose, the one with lowest AIC is generally considered to be closer with real data.

Another widely used information criteria is the Bayesian Information Criteria (BIC). It is derived within a Bayesian framework as an estimate of the Bayes factor for two competing models [63]. The BIC is defined as:

$$
\text { B I } C=-2 \log p(L)+p \log (n)
$$

It relies on the assumption that, the true model is in the candidate set which makes it asymptotically less optimal. Superficially, BIC differs from AIC on sample size $n$.

Performance of the model selection criteria in selecting good model for the observed data is examined using simulation studies. For application purpose, the AIC and BIC do have the same aim in identifying good model even if they differ in their exact definition.

Once an appropriate model had been entertained and its parameters estimated, the BoxJenkins methodology required examining the residuals of the actual values minus those estimated through the model. If such residuals are random, it is assumed that the model is appropriate. If not, another model is entertained, its parameters estimated and its residuals checked for randomness. In practically all instances a model could be found to result in random residuals. Several tests (the Box-Pierce Statistic, Ljung-Box Q statistic) have been suggested to help users determine if overall the residuals are indeed random.

For moderately long series and k not too small, the S.E.'s for the autocorrélations and partial autocorrelations of the residual series, $r_{k}(\widehat{\alpha})$ and $p_{k}(\widehat{\alpha})$, are obtained in the usual way. But for small $\mathrm{k}$, Box $\&$ Pierce [64], show that this can no longer be done.

Kwan, Sim \& Wu [65] indicated that the normalization procedure used in Box-Pierce test is inappropriate for an independent and identically distributed (i.i.d) normal series with an unknown mean. Consequently, the poor empirical performance of the test is not entirely unexpected. On other hand, Arranz [66] showed that in finite samples its distribution falls apart from the asymptotic one. After some discussions about the finite sample distribution of the test statistic, Ljung and Box [67] proposed a modified version of that test and defined: 


$$
Q(\hat{\rho})=n(n+2) \sum_{v=1}^{k} \frac{\hat{\rho}_{v}^{2}}{n-v}
$$

Where, $\hat{\rho}_{\mathrm{v}}$ is the sample autocorrelation of order $\mathrm{v}$ and $\mathrm{k}$ is the number of lags with sample size $\mathrm{n}$.

Ljung and Box showed that their test provides a substantially improved approximation to Chi-squared distribution with k-p-q degrees of freedom that should be adequate for most practical purposes with the same critical region as Box \& Pierce.

Forecasting is the final step of ARIMA model, which is an essential application of time series analysis. It is the prediction values based on identified past values of that variable or other related variable. For predicting a future value $\mathrm{y}_{\mathrm{h}+\mathrm{n}}$, $(\mathrm{h}=$ hence from $\mathrm{n}=$ now), of a stationary zero-mean series, given the realisation to date $\left\{\mathrm{y}_{1}, \mathrm{y}_{2}, \ldots \ldots, \mathrm{y}_{\mathrm{n}}\right\}$, but no other data.
Any forecast of $y_{h+n}$ will evidently be some function of $\mathrm{y}_{1}, \mathrm{y}_{2}, \ldots \ldots, \mathrm{y}_{\mathrm{n}}$ and we will restrict ourselves to just linear functions, that is to the class of linear forecasts.

The Mean Absolute Percentage Error (MAPE) also referred as Mean Absolute Percentage Deviation (MAPD) is one of the most popular measures of the forecast accuracy due to its advantages of scaleindependency and interpretability [68,69]. It produces infinite or undefined values, when the actual values are zero or closer to zero. If the actual value is very small (less than one), the MAPE yields extremely large percentage errors or outliers. Makridakis [70], attempts to resolve this problem by excluding outliers that have actual value less than one or Absolute Percentage Error (APE) values greater than the MAPE plus three S.D.

The scale of judgement using MAPE equation given by Lawrence et al., [71] is shown in Table-4 .

Table-4: Scale of Judgement of Forecast Accuracy

\begin{tabular}{|l|l|l|}
\hline Sl. No & MAPE & Judgement of Forecast Accuracy \\
\hline 1 & $<10 \%$ & Highly Accurate Forecast \\
\hline 2 & $11 \%-20 \%$ & Good Forecast \\
\hline 3 & $21 \%-50 \%$ & Reasonable Forecast \\
\hline 4 & $>51 \%$ & Inaccurate Forecast \\
\hline
\end{tabular}

Let $A_{t}$ and $F_{t}$ denotes the actual and forecast value at specified time ' $t$ ' respectively. Then MAPE is defined as [72],

$$
M A P E=\frac{1}{N} \sum_{t=1}^{N}\left|\frac{A_{t}-F_{t}}{A_{t}}\right|
$$

Where, $\mathrm{N}$ is the number of data points. When MAPE is multiplied by $100 \%$, it is called as APE. This measure is generally only used when quantity of interest is strictly positive.

\section{OUTPUT AND DISCUSSION}

In this paper, the past S\&P BSE stock price data from $1^{\text {st }}$ January, 2014 to $31^{\text {st }}$ December, 2019 is used to find out that the data are normally distributed and feasible to forecast for future stock price and the data from $1^{\text {st }}$ January, 2020 to $31^{\text {st }}$ January, 2020 will be used as validation for compare with the forecast data.

\section{DESCRIPTIVE ANAL YSIS}

The S \& P BSE stock price having a total number of 1478 observations is used in this study was taken from the official website of Bombay Stock Exchange. Closed stock price is choosen for this study because it reflects all the activities of the index in an entire trading day. Various descriptive statistics are calculated in order to describe the basic characteristics of the index with the help of SPSS and E Views Software. Table -5 represents the descriptive analysis of the S \& P BSE stock price data.

Table-5: Summary of Descriptive Statistics

\begin{tabular}{|l|l|l|l|l|l|}
\hline Range & Minimum & Maximum & Sum & Mean & \\
\hline Statistic & Statistic & Statistic & Statistic & Statistic & S.E \\
\hline 21488.19 & 20193.35 & 41681.54 & 45085805.72 & 30504.60 & 136.49 \\
\hline Std. Dev. & Variance & Skewness & \multicolumn{4}{|l|}{ Kurtosis } \\
\hline Statistic & Statistic & Statistic & S.E & Statistic & S.E \\
\hline 5247.44 & 27535624.52 & 0.263 & 0.064 & -0.983 & 0.127 \\
\hline
\end{tabular}

During the study period, the result quantified that, S \& P BSE stock price has the mean of Rs. 30504.60 with S.D. of Rs. 5247.44 and the range was Rs. 21488.19 with Rs. 41681.54 as maximum and Rs. 20193.35 as minimum values. Similarly, Skewness for the daily stock price is within the permissible limit
(0.263), which indicates that data are normally distributed. Kurtosis or convexity of the curve is the peakedness of the distribution and should be lies between -3 to +3 . From the above table the kurtosis is 0.983 , which is within the limit. 
The S.E of mean play a very important role in large sample theory and forms the basis of the testing of hypothesis. For any statistic, the large sample;

$$
\mathrm{Z}=\frac{\text { Statistic }-\mathrm{E}(\text { Statistic })}{\text { S. E }(\text { Statistic })} \sim \mathrm{N}(0,1)
$$

Thus, if the discrepancy between the observed and expected / hypothetical value of a statistic is greater than $\mathrm{Z}_{\propto}$ times its $\mathrm{S}$.E, the null hypothesis is rejected at $\propto \%$ level of significance. Similarly, if

$\mid$ Statistic $-\mathrm{E}($ Statistic $) \mid \leq \mathrm{Z}_{\propto}$. S. E (Statistic)

The deviation is not regarded significant at $5 \%$ level of significance. It also enables us to determine the probable limits within which the population parameter may be expected to lie. So the descriptive statistics shows that the values are normally distributed about its mean and variance.

\section{Model Identification}

The first step is to identify an ARIMA model to determine the order of differencing to make the series stationary. Figure $1 \& 2$ shows the general view of the $S$ $\&$ P BSE stock price in original pattern and difference at level one. From the below figure it is seen that the series is non stationary in Figure-1 and have a strong upward trend. This is basically describing on average what is the value doing for this series on a long period of time. Whereas, Figure- 2 is a stationary series with constant mean and variance over a long period of time. A stationary data set will allow predicting our model that the mean and variance will be same in future. The stationarity could be identified according to the tstatistic values in ADF and PP unit root test. In other words, if the t-statistic value exceeds the calculated value, then the series is considered as stationary. In Table- $6 \& 7$ the model checking was done with ADF and PP Unit Root Test.

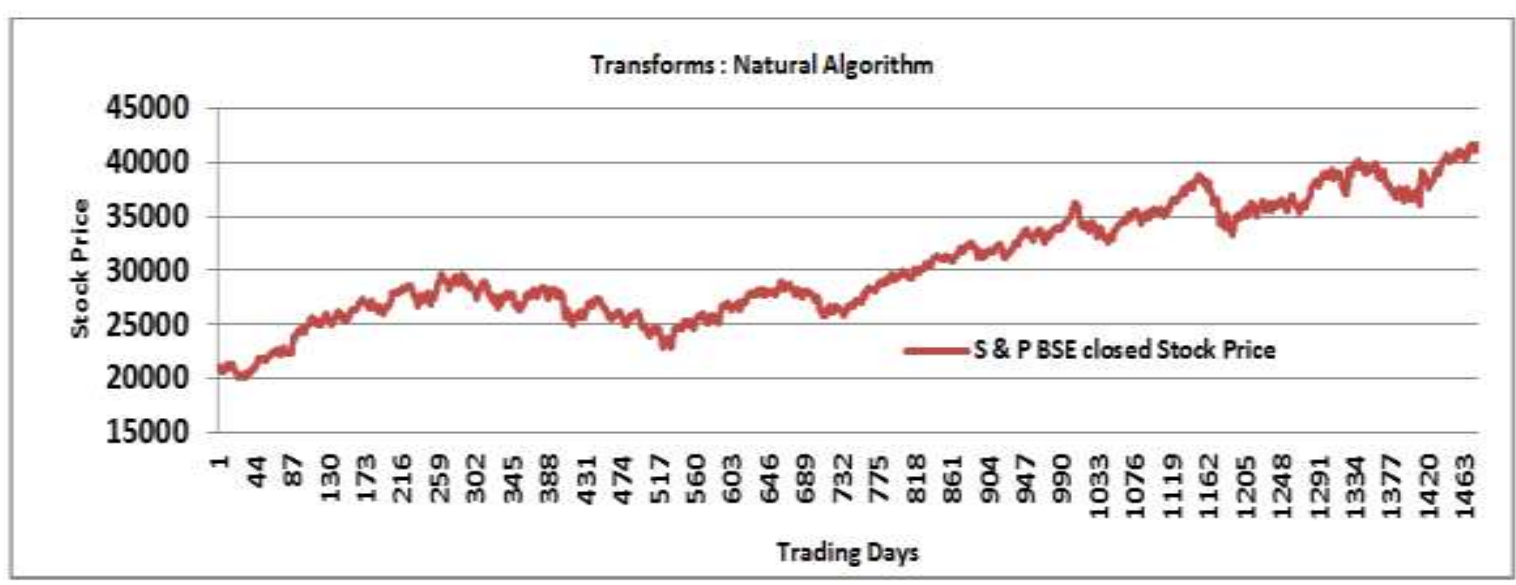

Fig-1: Graphical representation of S\&P BSE stock price in original pattern

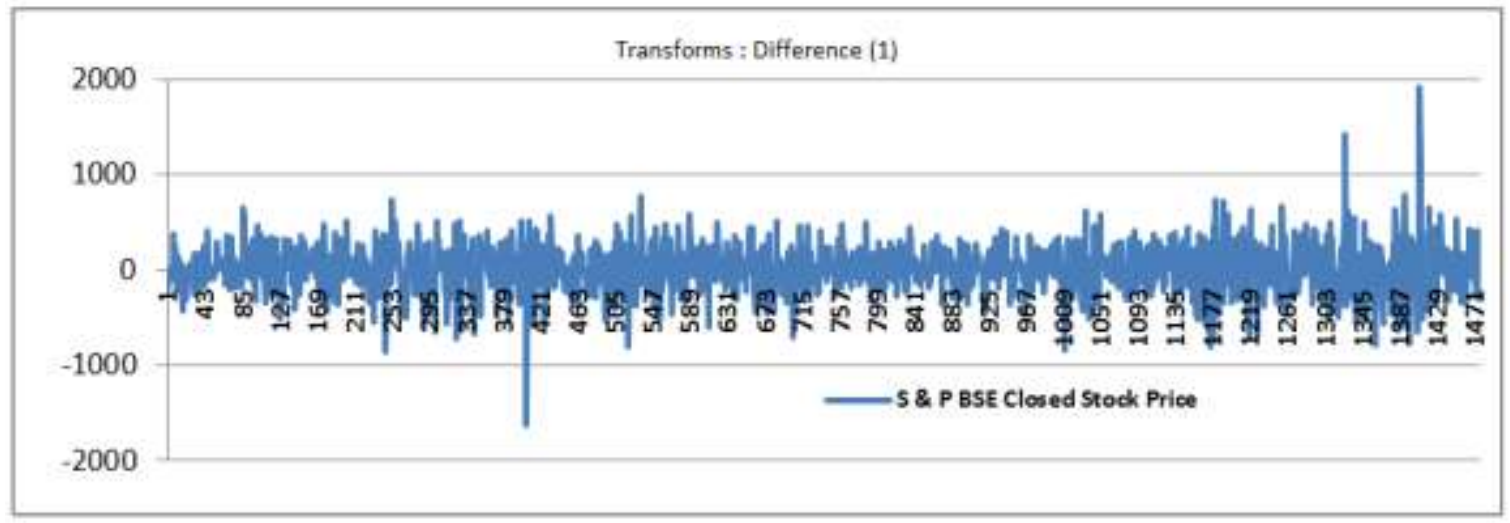

Fig-2: Graphical representation of S\&P BSE stock price after first difference 
Table-6: Augmented Dickey - Fuller Unit Root Test

\begin{tabular}{|c|c|c|c|c|}
\hline \multicolumn{4}{|c|}{ Null Hypothesis: D(CLOSE) has a unit root } & \\
\hline \multicolumn{5}{|c|}{ Exogenous: Constant, Linear Trend } \\
\hline \multicolumn{5}{|c|}{ Lag Length: 0 (Automatic - based on AIC, Maxlag=23) } \\
\hline & & & t-Statistic & Prob.* \\
\hline \multicolumn{3}{|c|}{ Augmented Dickey-Fuller test statistic } & -35.78291 & 0.0000 \\
\hline \multirow[t]{3}{*}{ Test critical values: } & $1 \%$ level & & -3.964274 & \\
\hline & $5 \%$ level & & -3.412857 & \\
\hline & $10 \%$ level & & -3.128415 & \\
\hline \multicolumn{4}{|c|}{ Included observations: 1476 after adjustments } & \\
\hline Variable & Coefficient & Std. Error & t-Statistic & Prob. \\
\hline $\mathrm{D}(\mathrm{CLOSE}(-1))$ & -0.930233 & 0.025997 & -35.78291 & 0.0000 \\
\hline $\mathrm{C}$ & 10.79192 & 13.24668 & 0.814688 & 0.4154 \\
\hline @TREND("1") & 0.002760 & 0.015518 & 0.177827 & 0.8589 \\
\hline R-squared & 0.465030 & \multicolumn{2}{|c|}{ Mean dependent var } & -0.035305 \\
\hline Adjusted R-squared & 0.464304 & \multicolumn{2}{|c|}{ S.D. dependent var } & 347.0640 \\
\hline S.E. of regression & 254.0205 & \multicolumn{2}{|c|}{ Akaike info criterion } & 13.91474 \\
\hline Sum squared resid & 95047434 & \multicolumn{2}{|c|}{ Schwarz criterion } & 13.92550 \\
\hline Log likelihood & -10266.08 & \multirow{2}{*}{\multicolumn{2}{|c|}{$\begin{array}{l}\text { Hannan-Quinn criter. } \\
\text { Durbin-Watson stat }\end{array}$}} & 13.91875 \\
\hline F-statistic & 640.2136 & & & 1.998013 \\
\hline Prob (F-statistic) & 0.000000 & & & \\
\hline
\end{tabular}

Table-7: Phillips and Perron Unit Root Test

\begin{tabular}{|c|c|c|c|c|}
\hline \multicolumn{4}{|c|}{ Null Hypothesis: D(CLOSE) has a unit root } & \\
\hline \multicolumn{4}{|c|}{ Exogenous: Constant, Linear Trend } & \\
\hline \multicolumn{5}{|c|}{ Bandwidth: 18 (Newey-West automatic) using Bartlett kernel } \\
\hline & & & Adj. t-Stat & Prob.* \\
\hline \multicolumn{3}{|c|}{ Phillips-Perron test statistic } & -35.69677 & 0.0000 \\
\hline \multirow[t]{3}{*}{ Test critical values: } & $1 \%$ level & & -3.964274 & \\
\hline & $5 \%$ level & & -3.412857 & \\
\hline & $10 \%$ level & & -3.128415 & \\
\hline \multicolumn{4}{|c|}{ *MacKinnon (1996) one-sided p-values. } & \\
\hline \multicolumn{4}{|c|}{ Residual variance (no correction) } & 64395.28 \\
\hline \multicolumn{4}{|c|}{ HAC corrected variance (Bartlett kernel) } & 54034.47 \\
\hline \multicolumn{4}{|c|}{ Included observations: 1476 after adjustments } & \\
\hline Variable & Coefficient & Std. Error & t-Statistic & Prob. \\
\hline $\mathrm{D}(\mathrm{CLOSE}(-1))$ & -0.930233 & 0.025997 & -35.78291 & 0.0000 \\
\hline $\mathrm{C}$ & 10.79192 & 13.24668 & 0.814688 & 0.4154 \\
\hline @TREND("1") & 0.002760 & 0.015518 & 0.177827 & 0.8589 \\
\hline R-squared & 0.465030 & \multicolumn{2}{|c|}{ Mean dependent var } & -0.035305 \\
\hline Adjusted R-squared & 0.464304 & \multicolumn{2}{|c|}{ S.D. dependent var } & 347.0640 \\
\hline S.E. of regression & 254.0205 & \multicolumn{2}{|c|}{ Akaike info criterion } & 13.91474 \\
\hline Sum squared resid & 95047434 & \multicolumn{2}{|c|}{ Schwarz criterion } & 13.92550 \\
\hline Log likelihood & -10266.08 & \multicolumn{2}{|c|}{ Hannan-Quinn criter. } & 13.91875 \\
\hline F-statistic & 640.2136 & \multicolumn{2}{|c|}{ Durbin-Watson stat } & 1.998013 \\
\hline Prob(F-statistic) & 0.000000 & & & \\
\hline
\end{tabular}

From the below table, the calculated values of ADF and PP test statistic for S \& P BSE stock price is less as compared to tabulated t-statistic at $1 \%, 5 \%$ and $10 \%$ level of significance and conforms the series becomes stationary after the first difference and avoid the problems of spurious regression. To add a high level answer to some of other answer that are good, but more detailed, it is an important because in its absence, a model describing the data will vary in accuracy at different time points.
After stationeries the time series by differencing, the next step to find out an ARMA model to identify the number of AR and / or MA terms to correct any autocorrelation that remains in the differenced series. The a.c.f represents the correlation between a time series and lags of itself, whereas, p.a.c.f is partial correlation of time series and its intermediate lags. Table- 8 represents the correlograms of S \& P BSE stock price after the first difference and their graphical representation are in Figure $3 \& 4$ 
Table-8: Correlogram of S \& P BSE stock price after the first difference

\begin{tabular}{|l|l|l|l|l|l|l|l|l|l|}
\hline Lag & 1 & 2 & 3 & 4 & 5 & 6 & 7 & 8 & 9 \\
\hline AC & 0.070 & -0.003 & -0.013 & -0.017 & -0.043 & -0.033 & -0.028 & -0.042 & 0.029 \\
\hline PAC & 0.070 & -0.008 & -0.012 & -0.015 & -0.041 & -0.027 & -0.024 & -0.040 & 0.033 \\
\hline Q-Stat & 7.196 & 7.208 & 7.458 & 7.864 & 10.606 & 12.181 & 13.307 & 15.924 & 17.205 \\
\hline Prob & 0.007 & 0.027 & 0.059 & 0.097 & 0.060 & 0.058 & 0.065 & 0.043 & 0.046 \\
\hline Lag & 10 & 11 & 12 & 13 & 14 & 15 & 16 & 17 & 18 \\
\hline AC & 0.045 & 0.029 & -0.009 & -0.022 & 0.010 & -0.041 & 0.015 & -0.007 & 0.005 \\
\hline PAC & 0.038 & 0.020 & -0.015 & -0.023 & 0.014 & -0.040 & 0.024 & -0.006 & 0.007 \\
\hline Q-Stat & 20.248 & 21.507 & 21.628 & 22.330 & 22.468 & 24.943 & 25.266 & 25.345 & 25.384 \\
\hline Prob & 0.027 & 0.028 & 0.042 & 0.050 & 0.070 & 0.051 & 0.065 & 0.087 & 0.115 \\
\hline
\end{tabular}

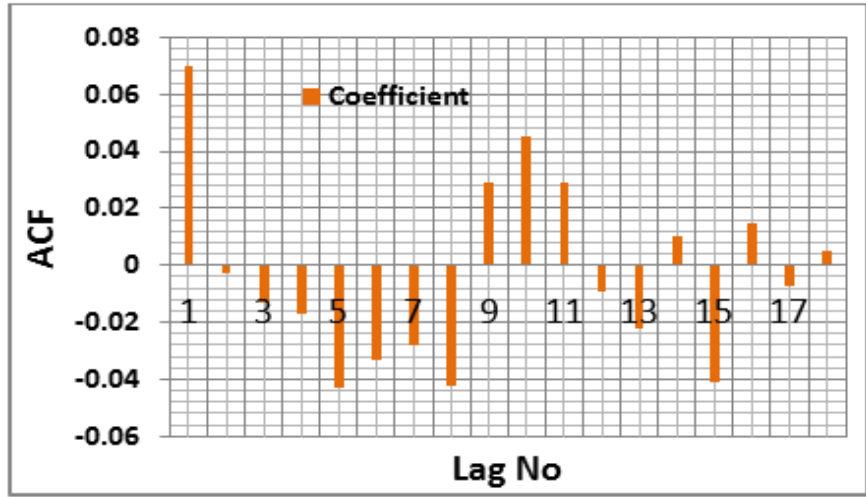

Fig-3: Autocorrelation Function

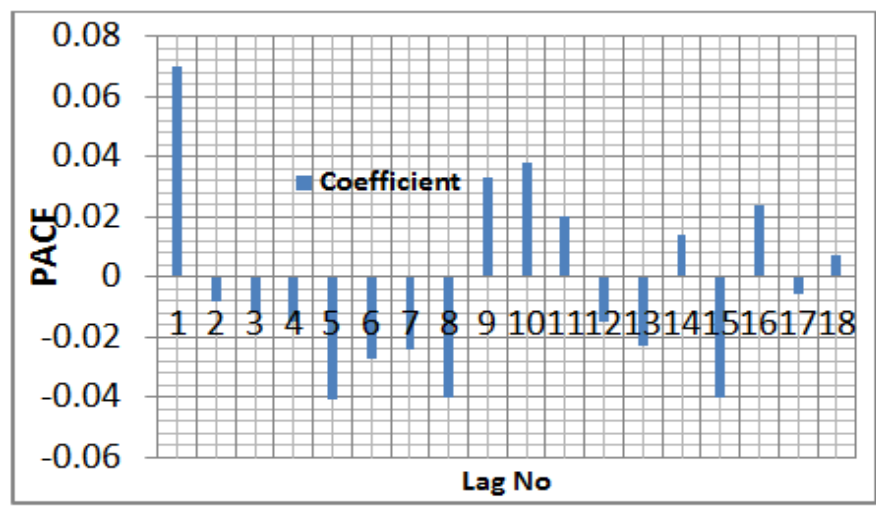

Fig-4: Partial Autocorrelation Function

From the above table and figure it is seen that:

- The p.a.c.f of the differenced series displayed a sharp cut-off at lag-1 and the lag-1 autocorrelation is positive.

- The a.c.f of the differenced series displayed a sharp cut-off at lag-1 and the lag-1 autocottrlation is positive.
So there is possibility of ARMA $(1,1)$ model of the above series. Looking at correlogram the possible models and their respective AIC and BIC values are summarized in Table-9.

Table-9: Different ARIMA model with their AIC and BIC values

\begin{tabular}{|c|c|c|c|c|c|c|c|c|c|c|}
\hline Model & $(0,1,1)$ & $(1,1,0)$ & $(1,1,1)$ & $(0,1,2)$ & $(2,1,0)$ & $(4,1,4)$ & $(2,1,1)$ & $(1,1,2)$ & $(4,1,1)$ & $(2,1,4)$ \\
\hline AIC & -6.7206 & -6.7204 & -6.7198 & -6.7196 & -6.7195 & -6.7188 & -6.7186 & -6.7186 & -6.7186 & -6.7186 \\
\hline $\mathrm{BIC}$ & -6.7099 & -6.7097 & -6.7055 & -6.7053 & -6.7051 & -6.6829 & -6.7007 & -6.7007 & -6.6935 & -6.6899 \\
\hline Model & $(0,1,3)$ & $(4,1,2)$ & $(3,1,0)$ & $(1,1,4)$ & $(3,3,3)$ & $(4,1,0)$ & $(0,1,4)$ & $(1,1,3)$ & $(3,1,1)$ & $(2,1,2)$ \\
\hline AIC & -6.7185 & -6.7185 & -6.7183 & -6.7183 & -6.7182 & -6.7181 & -6.7179 & -6.7173 & -6.7173 & -6.7173 \\
\hline $\mathrm{BIC}$ & -6.7005 & -6.6898 & -6.7004 & -6.6932 & -6.6895 & -6.6966 & -6.6963 & -6.6958 & -6.6958 & -6.6958 \\
\hline Model & $(4,1,3)$ & $(3,1,2)$ & $(2,1,3)$ & $(0,1,0)$ & $(3,1,4)$ & & & & & \\
\hline AIC & -6.7172 & -6.7171 & -6.7171 & -6.7164 & -6.7154 & & & & & \\
\hline $\mathrm{BIC}$ & -6.6849 & -6.6920 & -6.6919 & -6.7092 & -6.6832 & & & & & \\
\hline
\end{tabular}


From the above table, ARIMA $(0,1,1)$ is considered as best ARIMA as it is based on least AIC and BIC values.

\section{Parameters Estimation}

The penalty function statistic which includes R-square, adjusted R-square, S.E of regression and Durbin-Watson statistic is summarizes in Table-10.

Table-10: Model fit Statistics

\begin{tabular}{|l|l|l|l|l|}
\hline Model & R-square & Adjusted R-square & S.R. of Regression & Durbin-Watson Statistic \\
\hline Model-1 & 0.005 & 0.004 & 0.008 & 2.000 \\
\hline
\end{tabular}

From the above table it is seen that both the Rsquare and adjusted R-square values are very low and conformed that the residuals are free from heteroskedasticity and the model is free from specification error. Similarly the S.E of regression provides the absolute response of the typical distance that the data points falls from the regression line. Since S.E. of regression $=0.8 \%$, it indicates that the observations are closer to fitted line. It also represents the average distance of the data points from the fitted line is about $0.8 \%$ fat.

The value of Durbin-Watson statistic $=2.000$ strongly suggested that, there is neither positive nor negative first order serial correlation in the series. From regression analysis aspect it also detects the absence of autocorrelation at the first lag in the preceding error terms.

\section{Diagnostic Checking}

The Ljung-Box Q statistic is a diagnostic tool used to test lack of fit. The test examines the k-lag autocorrelation of the residuals. If the auto correlation is very small, we conclude that the model does not exhibit significant lack of fit.

Table-11: Ljung-Box Q statistic (18)

\begin{tabular}{|l|l|l|l|}
\hline Model & Statistic & d.f. & Sig. \\
\hline Model-1 & 16.912 & 17 & 0.460 \\
\hline
\end{tabular}

From the above table Ljung-Box Q statistic > $10 \%$, and indicates that the model has significant good fit to the S \& P BSE stock price data. The residual a.c.f and p.a.c.f are used to examine the residuals obtained from estimated model for significance of autocorrelation.

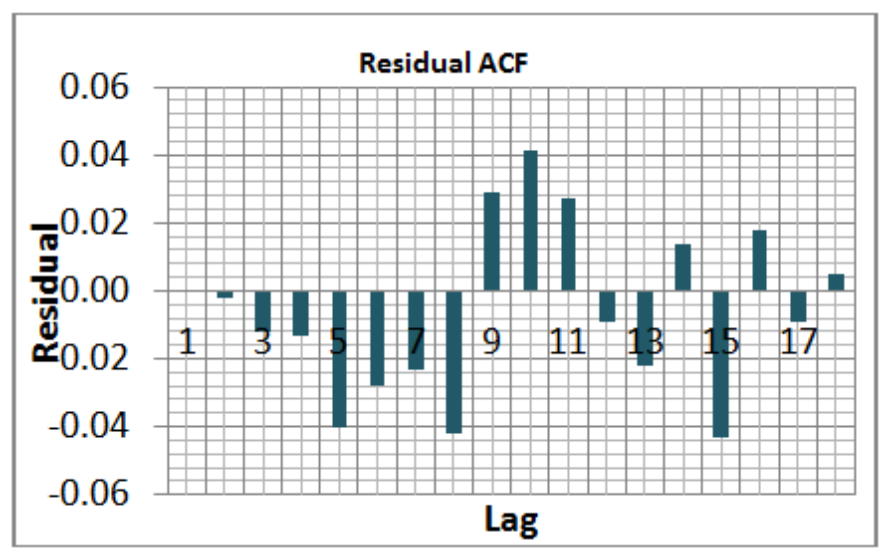

Fig-5: Residual ACF

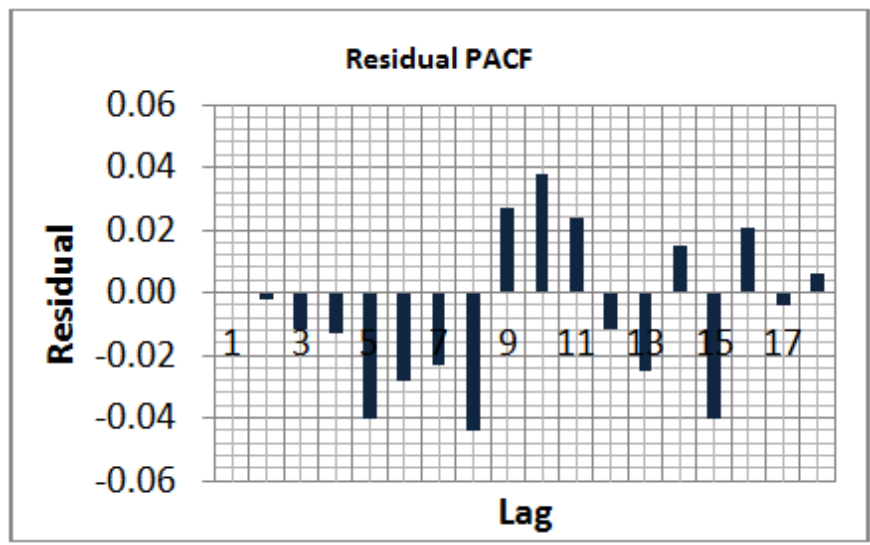

Fig-6: Residual PACF 
From the residual analysis in Figure $5 \& 6$, it was found that, the residual autocorrelation are equal to zeros at different choosen number of lags and indicated a good fit.

\section{Forecasting}

From the methodology stated above, the forecasted S \& P BSE stock price using forecasting equation for a period of 23 days, from $1^{\text {st }}$ January, 2020 to $31^{\text {st }}$ January, 2020 is performed and illustrated in Figure-7.

The forecasting equation

$$
Y_{t}=0.000452-0.076362 \varepsilon_{t-1}
$$

is based in the constant term and the coefficient of MA (1) is presented in the Table-12.

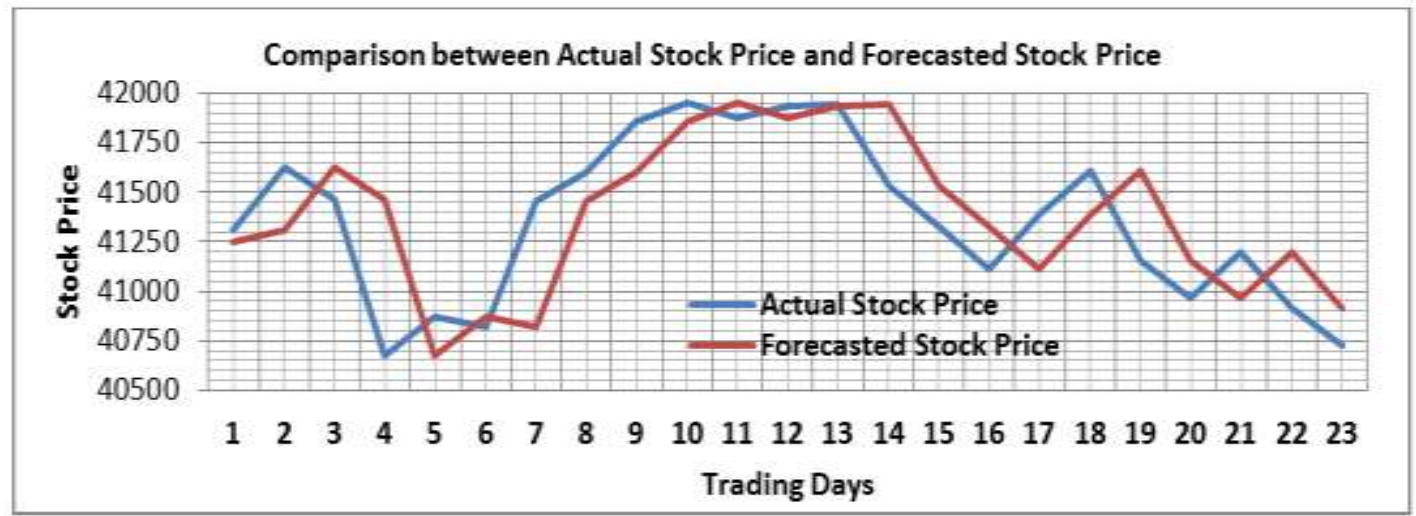

Fig-7: Comparison between Actual Stock Price and Forecasted Stock Price

Table-12: Parameters of ARIMA $(0,1,1)$ Model Estimation

\begin{tabular}{|l|l|l|l|l|l|}
\hline Model & Variable & Coefficient & S.E. & t-statistic & Prob. \\
\hline \multirow{2}{*}{ Model-1 } & Const. & 0.000452 & 0.000237 & 1.909114 & 0.0564 \\
\cline { 2 - 6 } & MA(1) & 0.076362 & 0.021637 & 3.529244 & 0.0004 \\
\hline
\end{tabular}

The correlation coefficient between forecasted stock price and actual stock price has a positive correlation $(\rho=0.699)$, which represents a strong relationship between actual stock price and forecast stock price due to stabilise its mean value in long-run.

\section{Forecast Accuracy}

Table-13: Mean Absolute Percentage Error (MAPE)

\begin{tabular}{|l|l|}
\hline Accuracy Measurement & MAPE \\
\hline Value & 8.56 \\
\hline
\end{tabular}

Since the MAPE $<10 \%$, it implies that the ARIMA $(0,1,1)$ model is highly accurate for forecasting the S\&P BSE stock price. Due to random behaviour of stock price, ARIMA model is highly suitable for future forecasting.

\section{CONCLUSIONS}

The presence of long memory in Bombay Stock Exchange stock price was explored by modeling and forecasting the series using Box-Jenkins ARIMA model. As shown in the results, the predicted price is much closer to the actual stock price, which indicates that the technique is very useful for any time series with any outline of change and it does not need the forecasters to pick any parameters in advance. Having a reliable statistical forecast model for predicting stock price, it is very crucial issue among investors, portfolio managers as well as researchers to take decision about investment. The main advantage of Box-Jenkins ARIMA model can be applied not only on investment decision tool but also in managing investment risk. It is also able to give high rate of profit returns, minimize the risk, investors need information as a reference for decision making of which stock they should buy, sell and maintain for future, which interest the investors. As a form of recommendation, different investors can choose companies according to their results, because the predictive power of Box-Jenkins ARIMA model gives high accurate result.

\section{REFERENCES}

1. Ray, S. (2012). Foreign Exchange Reserve and its impact on Stock Market Capitalization: Evidence from India. Research on Humanities and Social Sciences. 2(2):46-60.

2. Wang, J. J., Wang, J. Z., Zhang, Z. G., \& Guo, S. P. (2012). Stock index forecasting based on a hybrid model. Omega, 40(6), 758-766.

3. Sterba, J., \& Hilovska, K. (2010). The implementation of hybrid ARIMA neural network prediction model for aggregate water consumption prediction. Aplimat-Journal of Applied Mathematics, 3(3), 123-131.

4. Wei, L. Y. (2013). A Hybrid Model based on ANFIS and Adaptive Expectation Genetic 
Algorithm to forecast TAIEX. Economic Modelling. 33:893-899.

5. Atsalakis, G. S., Dimitrakakis, E. M., \& Zopounidis, C. D. (2011). Elliott Wave Theory and neuro-fuzzy systems, in stock market prediction: The WASP system. Expert Systems with Applications, 38(8), 9196-9206.

6. Kings, W. I. (1932). Forecasting Methods Successfully Used Since 1928. Journal of the American Statistical Association. 27(179):315319.

7. Cowels, A. (1933). Can Stock Market Forecasters Forecast? Econometrica. 1:309-324.

8. Lucas, R. E. (1976). Econometric Policy Evaluation: A Critique, In Caenegie-Rochester Conference Series, The Philip Curve, North Holland, Amsterdam. 19-46.

9. Zotteri, G., Kalchschmidt, M., \& Caniato, F. (2005). The impact of aggregation level on forecasting performance. International Journal of Production Economics, 93, 479-491.

10. Wadi, S. A., \& Ismail, M. T. (2011). Selecting Wavelet Transforms Model in Forecasting Financial Time Series Data Based on ARIMA Model. Applied Mathematical Sciences. 5(7):315326.

11. Pai, P., \& Lin, C. (2005). A Hybrid ARIMA and Support Vector Machines Model in Stock Price Prediction. Omega, 33:497-505.

12. Uma Devi, B., Sundar, D., \& Ali, P. (2013). An Effective Time Series Analysis for Stock Trend Prediction Using ARIMA Model for Nifty Midcap-50. International Journal of Data Management Process (IJDKP). 3(1):65-78.

13. Kyungjoo, L. C. (2007). Neural Network Model vs. SARIMA Model in Forecasting Korean Stock Price Index (KOSPI). Issues in Information System. 8(2):372-378.

14. Merh, N., Saxena, V. P., \& Pardasani, K. R. (2010). A comparison between hybrid approaches of ANN and ARIMA for Indian stock trend forecasting. Business Intelligence Journal, 3(2), 23-43.

15. Meyler, A., Kenny, G., \& Quinn, T. (1998). Forecasting Irish Inflation using ARIMA Models", Central Bank of Ireland Research Department, Technical Paper, 3/RT/1998.

16. Tabachnick, B. G., \& Fidell, L. S. (2001). Using Multivariate Statistics, $4^{\text {th }}$ Edition, Allyn \& Bacon, ISBN-10: 0321056779.

17. Javier, C., Rosario, E., Francisco, J. N., \& Antonio, J. C. (2003). ARIMA models to predict next electricity price. IEEE Transactions on Power Systems, 18(3), 1014-1020.

18. Khasel, M., Bijari, M., \& Ardali, G. A. R. (2009). Improvement of Auto-Regressive Integrated Moving Average models using Fuzzy logic. Neurocomputing. 956-967.
19. Mitra, S. K. (2009). Optimal Combination of Trading Rules Using Neural Networks. International Business Research. 2(2):86-99.

20. Atsalakis, G. S., \& Kimon, P. V. (2009). Forecasting Stock Market Short-term trends using a Neuro-Fuzzy Methodology. Expert Systems with Applications. 36(7):10696-10707.

21. Lee, C., \& Ho, C. (2011). Short-term load forecasting using lifting scheme and ARIMA model. Expert System with Applications. 38(5):5902-5911.

22. Awajan, A. M., Ismail, M. T., \& Al Wadi, S. (2017). A Hybrid EMD-MA for forecasting Stock market Index. Italian Journal of Pure and Applied Mathematics. 38(1):1-20.

23. Askari, M., \& Askari, H. (2011). Time Series Grey System Prediction-based Models: Gold Price Forecasting. Trends in Applied Sciences Research. 6:1287-1292.

24. Wong, H. L., Tu, Y. H., \& Wang, C. C. (2010). Application of fuzzy time series models for forecasting the amount of Taiwan export. Expert Systems with Applications, 37(2), 1465-1470.

25. Ojo, J. F., \& Olatayo, T. O. (2009). On the Estimation and Performance of Subset Autoregressive Integrated Moving Average Models. European Journal of Scientific Research. 28(2):287-293.

26. Ozaki, T. (1977). On the order determination of ARIMA models. Journal of the Royal Statistical Society, Series C (Applied Statistics). 26(3):290301.

27. Shittu, O. I., \& Yaya, O. S. (2009). Measuring Forecast Performance of ARMA and ARFIMA Models: An Application to US Dollar/UK Pound Foreign Exchange Rate. European Journal of Scientific Research. 32(2):167-176.

28. Tseng, F. M., Tzeng, G. H., Yu, H. C., \& Yuan, B. J. (2001). Fuzzy ARIMA model for forecasting the foreign exchange market. Fuzzy sets and systems, 118(1), 9-19.

29. Mandal, P., Shit, L., \& Goswami, S. (2014). Study of Effectiveness of Time Series Modelling (ARIMA) in Forecasting Stock Prices. International Journal of Computer Science, Engineering and Applications (IJCSEA). 4(2):1329.

30. Jadhav, S. (2015). Indian Share Market Forecasting with ARIMA Model. International Journal of Advanced Research in Computer and Communication Engineering. 4(11):334-336.

31. Edward, A., \& Manoj, J. (2016). Forecasr Model using ARIMA for Stock Prices of Automobile Sector. International Journal of Research in Finance and Marketing. 6(4):1-9.

32. Simons, D., \& Laryea, S. A. (2004). Testing the Efficiency of selected African Stock Markets, A Working Paper. 
33. Rahman, S., \& Hossain M. F. (2006). Weak Form Efficiency: Testimony of Dhaka Stock Exchange. Journal of Business Research. 8:1-12.

34. Majhi, R., Panda, G., Majhi, B., \& Sahoo, G. (2009). Efficient prediction of stock market indices using adaptive bacterial foraging optimization (ABFO) and BFO based techniques. Expert Systems with Applications, 36(6), 10097-10104.

35. Uko, A. K., \& Nkoro, E. (2012). Inflation Forecasts with ARIMA, Vector Autoregressive and Error Correction Models in Nigeria. European Journal of Economics, Finance \& Administrative Science. 50:71-87.

36. Asteriou, D., \& Hall, S. G. (2015). Applied Econometrics, 3rd Edition, Palgrave Macmillan, ISBN-10: 1137415460.

37. Box, G. P. E., \& Jenkins, G. M. (1976). Time Series Analysis: Forecasting and Control, Holden Day: San Francisco.

38. Groff, G. K. (1973). Empirical Comparison of Models for Short-Range Forecasting. Management Science. 20(1):22-31.

39. Geurts, M. D., \& Ibrahim, I. B. (1975). Comparing the Box-Jenkins Approach with the Exponentially Smoothed Forecasting Model Application to Hawaii Tourists. Journal of Marketing Research, 12:182-188.

40. Makridakis, S., \& Hibon, M. (1979). Accuracy of Forecasting: An Empirical Investigation. Journal of the Royal Statistical Society, Series A. 142(2):79-145.

41. Huss, W. R. (1985). Comparative Analysis of Company Forecasts and Advanced Time Series Techniques in the Electric Utility Industry. International Journal of Forecasting. 1:217-239.

42. Fildes, R., Hibon, M., Makridakis, S., \& Meade, N. (1995). The accuracy of extrapolative forecasting methods: additional empirical evidence. INSEAD.

43. Pankratz, A. (1991). Forecasting with Dynamic Regression models, $1^{\text {st }}$ Edition, WileyInterscience, ISBN-10: 1853105848.

44. Box, G. E. P., \& Tiao, G. C. (1975). Intervention Analysis with Applications to Economic and Environmental Problems. Journal of the American Statistical Association. 70:70-79.

45. Yule, G. U. (1926). Why do we sometimes get Nonsense-Correlations between time series? A Study in Sampling and the Nature of Time Series. Journal of Royal Statistical Society. 89:1-64.

46. Slutsky, E. (1937). The summation of random causes as the source of Cyclic Processes. Econometrica, 5:105-146.

47. Walker, A. M. (1952). Some properties of asymptotic power functions of goodness of fit tests for linear autoregressive schemes. Journal of Royal Statistical Society, Series-B. 14:117-134.

48. Yaglom, A. M. (1958). Correlation theory of processes with random stationary nth increments.
American Mathematical Society Translations. 2:87-141.

49. Chatfield, C., \& Prothero, D. L. (1973). BoxJenkins Seasonal Forecasting: Problems in a Case Study. Journal of the Royal Statistical Society A, 136:295-336

50. Granger, C. W. J., \& Nelson, H. (1978). Experience using the Box-Cox Transformation when Forecasting Economic Time Series, Working Paper. 78(1), Department of Economics, U.C.S.D.

51. Dickey, D., \& Fuller, W. (1979). Distribution of the estimators for autoregressive time series with a unit root. Journal of the American Statistical Association, 74:427-431.

52. Hamilton, J. (1994). Time Series Analysis, Princeton University Press, New Jersey, ISBN: 9780691042893

53. Said, S. E., \& Dickey, D. (1984). Testing for unit roots in autoregressive moving average models with unknown order. Biometrika, 71:599-607.

54. Ng, S., \& Perron, P. (1995). Unit Root Tests in ARMA Models with Data-Dependent Methods for the Selection of the Truncation Lag. Journal of the American Statistical Association. 90:268-281.

55. Schwert, G. W. (1989). Why does stock market volatility change over time? Journal of Finance. 44:1207-1239.

56. Phillips, P. C. B., \& Perron, P. (1988). Testing for Unit Roots in Time Series Regression. Biometrika, 75:335-346.

57. Bartlett, M. S. (1946). On the Theoretical Specification of Sampling Properties of Autocorrelated Time Serie. Journal of Royal Statistical Society, B. 8:27-41.

58. Quenouille, M. H. (1949). Approximate Tests of Correlation in Time Series, J.R.S.S., B 11, 1949:68-84.

59. Anderson, O. T. (1974). Identifying Box-Jenkins Processes. Computer Applications. 275-283.

60. Box, G. E. P., \& Jenkins, G. M. (1970). Time Series Analysis: Forecasting and Control. Holden Day, San Francisco

61. Akaike, H. (1973). Information Theory and an Extension of the Maximum Likelihood Principle, In: Petrov, B. N., \& Csaki, F. (eds.), $2^{\text {nd }}$ International Symposium on Information Theory: 267-81 Budapest: Akademiai Kiado.

62. Zucchini, W. (2000). An Introduction to Model Selection. Journal of Math. Psychology. 44(1):4161.

63. Schwarz, G. (1978). Estimating the dimension of a model. The annals of statistics, 6(2), 461-464.

64. Box, G. E., \& Pierce, D. A. (1970). Distribution of residual autocorrelations in autoregressiveintegrated moving average time series models. Journal of the American statistical Association, 65(332), 1509-1526.

65. Kwan, A. C., Sim, A. B., \& Wu, Y. (2005). A comparative study of the finite-sample 
performance of some portmanteau tests for randomness of a time series. Computational statistics \& data analysis, 48(2), 391-413.

66. Arranz, M. A. (2005). Portmanteau test statistics in Time Series, Tol-Project, file://C:/Users /TB\%20FIELD\%20OFFICER/Downloads/ndmtest .pdf.

67. Ljung, G. M., \& Box, G. E. P. (1978). On a measure of lack of fit in time series models. Biometrika, 65(2):297-303.

68. Hanke, J. E., \& Reitsch, A. G. (1995). Business Forecasting, Englewood Cliffs, NJ: Prentice-Hall, $5^{\text {th }}$ edition.
69. Bowerman, B. L., O’Connell, R. T., \& Koehler, A. B. (2004). Forecasting, Time Series and Regression: An Applied Approach, Belmont, CA: Thomson Brooks/Cole, $4^{\text {th }}$ edition.

70. Makridakis, S. (1993). Accuracy Measures: Theoretical and Practical Concerns. International Journal of Forecasting. 9:527-529.

71. Lawrence, K. D., Klimberg, R. K., \& Lawrence, S. M. (2009). Fundamentals of forecasting using excel. Industrial Press Inc.

72. Tofallis, C. (2015). A better measure of relative prediction accuracy for model selection and model estimation. Journal of the Operational Research Society, 66(8), 1352-1362. 